\title{
İzmir İli Ödemiş İlçesinde Damızlık Sığır Yetiştiricileri Birliği Üyesi İşletmelerde Sığırların Barındırılması
}

\author{
Erdal Yaylak $^{1}$, Yusuf Konca ${ }^{2}$, Nursel Koyubenbe ${ }^{3}$ \\ ${ }^{I}$ Süleyman Demirel Üniversitesi, Ziraat Fakültesi, Zootekni Bölümü, 32260 Isparta, Turkiye \\ ${ }^{2}$ Erciyes Üniversitesi, Ziraat Fakültesi, Zootekni Bölümü, 38039 Kayseri, Türkiye \\ ${ }^{3}$ Ege Üniversitesi, Ödemiş Meslek Yüksekokulu, 35750 Ödemiş/İzmir, Türkiye
}

M A K A L E B İ L G İ S İ

Geliş 21 Kasım 2014

Kabul 12 Ocak 2015

Çevrimiçi baskı, ISSN: 2148-127X

Anahtar Kelimeler:

Süt sığırcilığı

Sürü büyüklüğü

Ahır tipi

Sağım sistemi

Yem depolama

"Sorumlu Yazar:

E-mail: erdalyaylak@sdu.edu.tr
Ö Z E T

Bu çalışmanın amacı, Ödemiş’te bulunan İzmir Damızlık Sığır Yetiştiricileri Birliği (DSYB) üyesi işletmelerde sı ğırların barındırma koşullarını saptamaktır. Bu amaçla Birlik üyeleri arasından oransal örnekleme yöntemiyle seçilmiş 92 işletme, inek sayılarına göre 3 gruba ayrılmıştır. İnek sayıları 1., 2. ve 3. gruptaki işletmeler için sırasıyla, $5-20 ; 21-40$ ve $41+$ baş olarak belirlenmiştir. Araştırma sonuçları, incelenen işletmelerdeki ahırların örtülülük derecesi bakımından \%8,7'sinin kapalı, \%15,2'sinin yarı kapalı ve \%76,1'inin sundurmalı tipte olduğunu göstermiştir. Sağmal ahırların $\% 6,5$ 'i toprak, \%19,6'sı beton ve \%73,9'u beton + toprak zemine sahiptir. İnek başına düşen ahır alanı 1., 2. ve 3. grup işletmeler için sırasıyla $22,2 \mathrm{~m}^{2} ; 19,5 \mathrm{~m}^{2} ; 18,2 \mathrm{~m}^{2}$ ' dir. Ahırların tam kapasite kullanılması durumunda inek başına 12,5 ile $15 \mathrm{~m}^{2}$ arasında alan düşmektedir. Ancak, incelenen işletmelerin hiçbiri mevcut ahır kapasitelerini tam olarak kullanamamıştır. Ahır kullanım kapasiteleri \%55 ile \%80 arasında değişmiştir. Yetiştiricilerin \%19,6'sı buzağılarını bireysel bölmelerde barındırmış, \%82,6'sı ahırlarını gece aydınlatmış ve $\% 64,1$ 'i yoğun yem deposuna sahiptir. İşletmelerin hepsinde inekler sağım makinaları ile sağılmaktadır. Sağım sistemleri içinde en yaygın olanı seyyar kovalı $(\% 47,8)$ sistem olup, bunu vakum hatlı sistem $(\% 37)$ ve sağımhane $(\% 15,2)$ takip etmektedir. İşletmelerin hiç birisinde gübre çukuru bulunmamaktadır. Sürü büyüklügünün artması ile işletmelerde daha fazla oranda serbest ahırın, doğum bölmesinin, yem deposunun ve süt soğutma tankının bulunduğu ortaya çıkmıştır. Sonuç olarak sürülerin büyümesi ile barındırmayla ilgili özelliklerde iyileşmelerin olduğu söylenebilir.

Turkish Journal Of Agriculture - Food Science And Technology, 3(5): 316-324, 2015

Cattle Housing at the Registered Farms under Cattle Breeders' Association in Ödemiş, İzmir.

\section{A R T I C L E I N F O}

\section{Article history:}

Received 21 November 2014

Accepted 12 January 2015

Available online, ISSN: 2148-127X

Keywords:

Dairy cattle

Herd size

Barn type

Milking system

Feed storage

\section{"Corresponding Author:}

E-mail: erdalyaylak@sdu.edu.tr

\section{A B S T R A C T}

The objective of this study was to determine barning conditions of dairy farms registered to Cattle Breeders Association (CBA) Ödemiş district of İzmir. The 92 farms were selected among members of the CBA by proportional sampling method. The farms were divided into three groups according to the number of cattle: group 1 from 5 to 20, group 2 from 21 to 40 and group 3 with over 41 heads, respectively. The farms were divided into three groups according to the number of cattle: 5-20; $21-40$ and over 41 heads, respectively. The research results indicated that $76.1 \%$ of the barns were shed type, $15.2 \%$ were corral, $8.7 \%$ were completely closed-up. The flooring types of these barns were a mixed of concrete and soil $(73.9 \%)$, concrete $(19.6 \%)$ and soil $(6.5 \%)$. The stocking density for group 1,2 and 3 were $22.2 \mathrm{~m}^{2}, 19.5 \mathrm{~m}^{2}$ and $18.2 \mathrm{~m}^{2}$ per cow, respectively. The barns had a range of full cattle capacity from $12.5 \mathrm{~m}^{2}$ to $15 \mathrm{~m}^{2}$ per cow. But none of the farms surveyed did not use fully capacity of the barn. The present running capacity of farms were between $55 \%$ and $80 \%$. It was observed that $19.6 \%$ of farms had a individual calf section, $82.6 \%$ had a night lighting at the barn, and $64.1 \%$ had a seperate concenrated feed store. All the farms were milked with milking machines. The percentage of farms with bucked milking machine was $47.8 \%$, those with an air pipeline system was $37 \%$ and those with parlour system was $15.2 \%$. None of farms had manure pit. Consequently, as herd size grow, the presence of free barn, calving pen, feed store and milk cooling tank increase. It can be concluded that improving the housing conditions is much more related with increasing the herd size per farm. 


\section{Giriş}

Sığırların et ve süt verimleri üzerinde genetik yapı ve çevrenin etkisi farklı düzeylerdedir. Verim üzerine etkili önemli çevresel faktörlerden birisi de barındırmadır. Barınaklar farklı yaş ve fizyolojik dönemlerdeki hayvanları barındıran ahırları, kaba ve yoğun yem depolarını, sağım ünitelerini, gübrelik ve sosyal tesis gibi binaları kapsamaktadır. Ülkemizde bölgeler arasında önemli ölçüde iklim farklılıkları vardır. Barınak yapılmadan önce, yörenin iklimsel verilerine, sürü varlığına ve işletmenin yetiştirme yönüne göre planlama yapılmalıdır. Bir ülke veya bölge ile ilgili ileriye dönük yapılacak planlamalar açısından mevcut durumun ve yetiştirici tercihlerinin bilinmesi gerekmektedir. Böylelikle bilimsel çalışmaların sonucunda elde edilen yeni bilgilerin aktarılması ve varsa yanlışların düzeltilebilmesi mümkün olabilecektir. Ülkemizde farklı bölgelerde sığır yetiştiriciliği yapan işletmelerin genel durumlarını ortaya koyan çok sayıda çalışma yapılmıştır (Saner, 1993; Oluğ, 1996; Erdoğan ve ark., 2004; Koyubenbe, 2005; Köse, 2006; Nizam, 2006; Soyak ve ark., 2007; Tatar, 2007; Elmaz ve ark., 2010; Aydın ve ark., 2014). Buna karşın sığırların barındırılmasına ilişkin sınırlı sayıda çalışma bulunmaktadır (Bardakçıŏglu ve ark., 2004; Tugay ve Bakır, 2004; Yaslığlu ve Arıc1, 2005; Kaygısız ve Tümer, 2009; Tilki ve ark., 2013). Bu çalışma ile önemli bir süt sığırı yetiştirme merkezi olan Ödemiş̧te sığırların barındırılması konusunda mevcut durum ortaya konacaktır. Elde edilen sonuçlar benzer bölgeler için fikir verebilecektir. Araştırmanın yapıldığ 1 Ödemiş ilçesi, İzmir Tarım İl Müdürlüğünün 2013 yılı verilerine göre, 115 bin baş sığır varlığı ve 453367 ton/yıl süt üretimi ile İzmir de en fazla sığırın bulunduğu (\%23) ve sütün üretildiği (\%33) ilçedir. Bu çalışma ile Ödemişte bulunan Damızlık Sığır Yetiştiricileri Birliği (DSYB) üyesi işletmelerdeki ahır tipleri, yem depoları, sağım üniteleri, aydınlatma ve gübreliklerin mevcut durumu ortaya konmuştur.

\section{Materyal ve Yöntem}

$\mathrm{Bu}$ araştırma, Ödemiş’te Siyah Alaca 1 rkı sığır yetiştiren DSYB üyesi işletmelerde 2008 yılının TemmuzEkim ayları arasında ankete dayalı olarak yürütülmüştür. Ana kitlenin belirlenmesinde İzmir DSYB kayitlarından yararlanılmıştır. Örnek hacmi, Ödemiş’te bulunan 2278 birlik üyesi arasından Miran (2002) tarafindan bildirilen oransal örnekleme yöntemiyle, $\% 95$ güven aralığ 1 ve $\% 10$ hata payı ile 92 işletme olarak belirlenmiştir. İşletmeler inek sayılarına göre 3 gruba ayrılmıştır. İşletme grupları; 1.grup; 5-20 baş inek, 2.grup; 21-40 baş inek, 3.grup; 41+ baş inek olarak oluşturulmuştur. Birinci, 2. ve 3. gruba giren işletme sayısı ve oranları sırasılya, 55 işletme $(\% 59,78), 29$ işletme $(\% 31,52)$ ve 8 işletme $(\% 8,70)$ 'dir. Verilerin analizinde gruplar arası karşılaştırmalarda, sayım ile elde edilen değişkenler için Khi-kare analizi, sürekli değişkenler için ise varyans analizi yapılmıştır. Ortalamaların karşılaştırılmasında Duncan testi kullanılmıştır. Kullanılan doğrusal model, $Y_{\mathrm{ij}}=\mu+\mathrm{a}_{\mathrm{i}}+\mathrm{e}_{\mathrm{ij}}$, olup; burada $\mathrm{Y}_{\mathrm{ij}}=$ inceleme konusu özellik (barınak alanı vb.); $\mu$ : genel ortalama; $a_{i}=$ işletme grupları; $e_{i j}=$ şansa bağlı hatayı ifade etmektedir. Verilerin analizinde SPSS (1999) istatistik paket programından yararlanılmıştır.

\section{Bulgular ve Tartışma}

\section{Incelenen İsletmelerdeki Ahırların Özellikleri}

Hayvanların verim kayıtları ve yönetim işlemlerinin kolayca takip edilmesi açısından önemli olan bürolar, incelenen işletmelerin çok azında (\%11) bulunmaktadır (Tablo 1). Şanlıurfa'da büyük $(150 \quad-2000$ baş $)$ işletmelerin \%41'inde idari bina bulunmaktadır (Yener ve ark., 2013).

Çalışmamızda ahırların sınıflandırılması, örtülülük derecelerine ve taban düzenlemesine göre yapılmıştır (Akman, 2003). Örtülülük derecesine göre, incelenen işletmelerde ahırların \%8,7'si kapalı; \%15,2'si yarı kapalı (üç tarafi duvarla çevrili, üstü örtülü) ve $\% 76,1$ 'i de sundurmalı (üç veya dört tarafı açık, üstü tamamen veya kısmen örtülü) tiptedir (Tablo 1). Ahır tipleri hayvan sayısı, bölgenin iklim koşulları ve bilimsel gelişmelere bağlı olarak değişebilmektedir. Aydın'da yapılan bir çalışmada kapalı ve yarı açı ahırların oranları sırasıyla $\% 4,7$ ve \%51,3'tür (Bardakçıoğlu ve ark., 2004). Uşak, Burdur, Hatay, Tekirdağ, Kahramanmaraş, Ankara ve Aksaray gibi illerde ahırların büyük çoğunluğunun kapalı bağlı veya kapalı duraklı ahır olduğu bildirilmiştir (Oluğ, 1996; Köse, 2006; Soyak ve ark., 2007; Tatar, 2007; Kaygısız ve Tümer, 2009). Hayvan sayısının artması ahır tipini değiştirmektedir. İşletme büyüklüğünün artması ile Ödemiş̧te sundurmalı ahır tipine sahip olan yetiştiricilerin oranı yükselirken, Burdur da ise yarı açık ahırlara sahip olanların oranı artmıştır (Oluğ, 1996).

Taban düzenlemesine göre ahırlar, bağlı duraklı $(\% 1,1)$, serbest durakl1 $(\% 25)$ ve serbest $(\% 73,9)$ ahır tipindedir. İnek sayısının en fazla olduğu 3. gruptaki işletmelerin hepsi sundurmalı ve serbest ahırlardan oluşmaktadır. Aydın ilinde farklı zamanlarda yapılan araştırmalarda kapalı bağlı ahırların Ödemiş'e göre daha yaygın olduğu (\%16-17) saptanmıştır (Nizam, 2006; Payık ve Kaya Kuyululu, 2012). Diğer yandan Ödemiş’te hayvan sayısının fazla olduğu 3. grupta serbest duraklı ahır bulunmazken, Nizam (2006) Aydın'da hayvan sayısının fazla olduğu (21+) grupta serbest duraklı ahırların oranı $(\% 76,5)$ yüksektir. Ödemiş ilçesine komşu olan Tire'de de açık ve serbest ahırlar bulgumuzdaki gibi yüksek oranda saptanmıştır (Öztürk ve Ünal, 2011). Bursa'da Yaslığlu ve Arıcı (2005) işletmelerin \%15'inde serbest-açık, \%42'sinde bağlı duraklı ve \%43'ünde serbest duraklı ahır sistemlerinin bulunduğunu bildirmiştir. Ödemiş'le karşılaştırıldığında, Bursa'da bağlı ve serbest duraklı ahırlar yaygındır.

Ödemiş’te serbest ahırların yaygın olmasının nedenlerinden birisinin Ziraat Bankası'nın kıyı ve ılıman bölgelere kredi desteği (Yüksel ve ark., 2004) vermesinin olduğu söylenebilir. Ayrıca, serbest ahırların inşaat maliyetinin inek sayısının 20 ve üzerinde olması durumunda düşmesi (Yüksel ve ark., 2004) ve yörenin iklim koşullarının uygun olması da serbest ahırların fazla olmasında etkilidir. Çalışma kapsamındaki işletmelerin yaklaşı $\% 40$ ' 120 baş ve üzerinde ineğe sahiptir.

İncelenen ișletmelerde sağmal ahırların zeminleri toprak $(\% 6,5)$, beton $(\% 19,6)$ ile beton ve topraktan $(\% 73,9)$ yapılmıştır. Serbest ahırlarda altlık kullanılmazken, serbest duraklı ahırlarda (23 adet) altlık olarak en fazla kum $(\% 52,2)$ ve toprak $(\% 39,1)$ 
kullanılmıștır (Tablo 1). Ahırlarda altlık kullanımı meme sağlığı, ayak-bacak ve tırnak sorunları ve hayvan refahı açısından önemlidir. Ahır zeminleri ve altlık malzemeleri yörelere göre değişebilmektedir. Örneğin Giresun ilinde barınak tabanı tahta $(\% 42,4)$, toprak $(\% 9,7)$ ve taştan $(\% 0,5)$ yapılmıştır. Bu ahırlarda altlık olarak gazel-fındıkpatos artığı $(\% 52)$, gazel $(\% 14,7)$ ve kuru gübre $(\% 14,2)$ kullanılmıştır (Tugay ve Bakır, 2004). Burdur da ahır zeminlerinin $\% 73,1$ 'i beton, $\% 24,5$ 'i toprak ve $\% 2,4$ 'ü taştan yapılmıștır (Elmaz ve ark., 2010). Aydın, Muş, Kahramanmaraş ile Ankara ve Aksaray illerinde altlık kullananların oranları \%5 ile \%90 arasında değişmiştir. Muş’ta daha çok kuru gübre (\%18.6), Kahramanmaraş’ta saman (\%60), Aydın da kum (\%4) kullanılmıştır (Kaygısız ve Tümer, 2009; Payık ve Kaya Kuyululu, 2012; Şeker ve ark., 2012). Kapalı ve bağlı ahırlarda altlık kullanımı artmaktadır. Çalışmamızda işletmelerin \%66'sında gezinme alanı bulunduğu saptanmıştır. Uşak'ta ise işletmelerin \%74'ünde gezinti alanı vardır (Köse, 2006).

Sığırların ve buzağıların barındırılması, yetiştiricilerin sürüyü büyütme istekleri, ayak banyosu ve doğum bölmesi bulunma durumları Tablo 2'de gösterilmiştir. Yetiştiricilerin \%53,3’ü sağmal, kurudaki inekler ve düveleri aynı bölmede barındırmaktadır. Sürü büyüklüğünün artması ile sağmal inekleri ayrı barındıranların oranı (\%32,7'den \%75'e) yükselmiştir $(\mathrm{P}<0,05)$. Yetiştiricilerin \%71'i inek sayılarını artırmak istemektedir. Tekirdağ ve Uşak'ta yetiştiricilerin \%8687'si hayvan sayılarını artırmayı düşünmektedir (Köse, 2006; Soyak ve ark., 2007). Yetiştiricilerin \%69'u kendi sürüsünden hayvanlarla sürüsünü büyütmek istemiştir. Buzağıların yaklaşık yarısı ahır içinde, yarısı da ahır dışında yetiştirilmektedir. Buzağıların bireysel barındırılması ile doğru bir şekilde beslenmeleri, birbirini emmelerinin önlenmesi ve hastalık bulaşma riski azaltılmaktadır. Çalıșmamızda yetiștiricilerin \%19,6'sı buzağılarını bireysel, \%80,4'ü grup olarak barındırmaktadır. Sürü büyüklüğü, bireysel barındırmayı artırmıştır. Uşak ili DSYB üyeleri bulgumuzdan daha fazla oranda buzağ 1 kulübesine sahipken (\%44), Aydın $(\% 6,1)$ ve Burdur' da $(\% 0,7)$ ise daha düşük orandadır (Bardakçıŏlu ve ark., 2004; Köse, 2006; Elmaz ve ark., 2010).

Sığırların ayak sağlığı açısından ayak banyolukları çok önemlidir. Ayak banyoluklarında dezenfektan kullanımı hastalıkları önlemekte ve tırnağı sertleştirmektedir (Akman, 2003). İncelenen işletmelerin $\% 6,5$ 'i ayak banyosuna sahiptir (Tablo 2). Doğum bölmesi, doğum öncesinde ve sonrasında hayvanların gözlenmesine, bakım ve beslenmesine imkan vermektedir. İşletmelerin \%38'inde doğum bölmesi bulunmaktadır. İşletmelerin büyümesi ile doğum bölmesi bulunduranların oranı (\%25,5'den \%62,5'e) artmıştır $(\mathrm{P}<0,05)$. Doğum bölmesi Aydın'da bulunan işletmelerde bulgumuzdan daha fazla $(\% 45,5)$ iken (Bardakçıoğlu ve ark. 2004), Ankara, Aksaray, Kahramanmaraş ve Burdur da ise daha düşük $(\% 6,5, \% 30)$ orandadır (Tatar, 2007; Kaygısız ve Tümer, 2009; Elmaz ve ark., 2010; Elmaz ve ark., 2010). Çalışmamızda doğum bölmelerinde altlık olarak ençok saman $(\% 51,4)$ ve toprak $(\% 34,3)$ kullanıldığı saptanmıştır.

Tablo 1 İșletme gruplarına göre ahır tipleri, ahır zeminleri ve altlıkla ilgili bilgiler

\begin{tabular}{|c|c|c|c|c|c|c|c|c|}
\hline \multirow[b]{3}{*}{ Özellikler } & \multicolumn{6}{|c|}{ İşletme grupları } & \multirow{2}{*}{\multicolumn{2}{|c|}{ Toplam }} \\
\hline & \multicolumn{2}{|c|}{ 1.grup } & \multicolumn{2}{|c|}{ 2. grup } & \multicolumn{2}{|c|}{ 3. grup } & & \\
\hline & $\mathrm{n}$ & $\%$ & $\mathrm{n}$ & $\%$ & $\mathrm{n}$ & $\%$ & $\mathrm{n}$ & $\%$ \\
\hline İşletmede büro varlığ $10 D$ & & & & & & & & \\
\hline Var & 4 & 7,3 & 5 & 17,2 & 1 & 12,5 & 10 & 10,9 \\
\hline Yok & 51 & 92,7 & 24 & 82,8 & 7 & 87,5 & 82 & 89,1 \\
\hline Örtülülük derecesine göre ahırlar ${ }^{\text {OD }}$ & & & & & & & & \\
\hline Kapalı & 6 & 10,9 & 2 & 6,9 & 0 & 0,0 & 8 & 8,7 \\
\hline Yarı kapalı (üç tarafı kapalı) & 9 & 16,4 & 5 & 17,2 & 0 & 0,0 & 14 & 15,2 \\
\hline Sundurmalı & 40 & 72,7 & 22 & 75,9 & 8 & 100 & 70 & 76,1 \\
\hline Taban düzenlemesine göre ahırlar ${ }^{\mathrm{OD}}$ & & & & & & & & \\
\hline Bağlı duraklı & 1 & 1,8 & 0 & 0,0 & 0 & 0,0 & 1 & 1,1 \\
\hline Serbest duraklı & 13 & 23,6 & 10 & 34,5 & 0 & 0,0 & 23 & 25,0 \\
\hline Serbest (duraksız) & 41 & 74,5 & 19 & 65,5 & 8 & 100 & 68 & 73,9 \\
\hline Sağmal ahır zemini ${ }^{O D}$ & & & & & & & & \\
\hline Toprak & 4 & 7,3 & 2 & 6,9 & 0 & 0 & 6 & 6,5 \\
\hline Beton & 13 & 23,6 & 5 & 17,2 & 0 & 0 & 18 & 19,6 \\
\hline Toprak ve beton & 38 & 69,1 & 22 & 75,9 & 8 & 100 & 68 & 73,9 \\
\hline Serbest duraklarda kullanılan altlık OD & & & & & & & & \\
\hline Kum & 7 & 53,8 & 5 & 50,0 & 0 & 0 & 12 & 52,2 \\
\hline Toprak & 5 & 38,5 & 4 & 40,0 & 0 & 0 & 9 & 39,1 \\
\hline Gübre & 1 & 7,7 & 1 & 10,0 & 0 & 0 & 2 & 8,7 \\
\hline Gezinme alanı bulunma durumu ${ }^{\mathrm{OD}}$ & & & & & & & & \\
\hline Var & 32 & 58,2 & 24 & 82,8 & 6 & 62,5 & 61 & 66,3 \\
\hline Yok & 23 & 41,8 & 5 & 17,2 & 3 & 37,5 & 31 & 33,7 \\
\hline
\end{tabular}


Tablo 2 Sağmalların ve buzağıların barındırılması, ayak banyosu ve doğum bölmesi bulunma durumları

\begin{tabular}{|c|c|c|c|c|c|c|c|c|}
\hline \multirow[b]{3}{*}{ Özellikler } & \multicolumn{6}{|c|}{ İşletme grupları } & \multirow{2}{*}{\multicolumn{2}{|c|}{ Toplam }} \\
\hline & \multicolumn{2}{|c|}{ 1.grup } & \multicolumn{2}{|c|}{ 2. grup } & \multicolumn{2}{|c|}{ 3. grup } & & \\
\hline & $\mathrm{n}$ & $\%$ & $\mathrm{n}$ & $\%$ & $\mathrm{n}$ & $\%$ & $\mathrm{n}$ & $\%$ \\
\hline Sağmal, kuru ve düvelerin barındırılması ${ }^{*}$ & & & & & & & & \\
\hline Ayrı bölmede & 18 & 32,7 & 19 & 65,5 & 6 & 75,0 & 43 & 46,7 \\
\hline Aynı bölmede & 37 & 67,3 & 10 & 34,5 & 2 & 25,0 & 49 & 53,3 \\
\hline 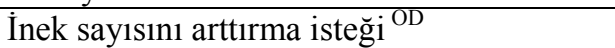 & & & & & & & & \\
\hline Evet & 37 & 67,3 & 22 & 75,9 & 6 & 75,0 & 65 & 70,7 \\
\hline Hayır & 18 & 32,7 & 7 & 24,1 & 2 & 25,0 & 27 & 29,3 \\
\hline Evetse hayvan temin yeri ${ }^{O D}$ & & & & & & & & \\
\hline Kendi sürümden & 23 & 62,2 & 18 & 81,8 & 4 & 66,7 & 45 & 69,2 \\
\hline Satın alma & 14 & 37,8 & 4 & 18,2 & 2 & 33,3 & 20 & 30,8 \\
\hline Buzağıların barındırılma yeri ${ }^{\mathrm{OD}}$ & & & & & & & & \\
\hline Ahır içi & 27 & 49,1 & 15 & 51,7 & 3 & 37,5 & 45 & 48,9 \\
\hline Ahır dişı & 28 & 50,9 & 14 & 48,3 & 5 & 62,5 & 47 & 51,1 \\
\hline Buzağıların barındırılma şekli ${ }^{\text {OD }}$ & & & & & & & & \\
\hline Bireysel & 10 & 18,2 & 4 & 13,8 & 4 & 50,0 & 18 & 19,6 \\
\hline Grup & 45 & 81,8 & 25 & 86,2 & 4 & 50,0 & 74 & 80,4 \\
\hline Ayak banyosu varlığ ${ }_{1}{ }^{O D}$ & & & & & & & & \\
\hline Var & 2 & 3,6 & 4 & 13,8 & 0 & 0,0 & 6 & 6,5 \\
\hline Yok & 53 & 96,4 & 25 & 86,2 & 8 & 100,0 & 86 & 93,5 \\
\hline Doğum bölmesi varlığ ${ }^{*}$ & & & & & & & & \\
\hline Var & 14 & 25,5 & 16 & 55,2 & 5 & 62,5 & 35 & 38,0 \\
\hline Yok & 41 & 74,5 & 13 & 44,8 & 3 & 37,5 & 57 & 62,0 \\
\hline Doğum Bölmesinde kullanılan altlık tipi ${ }^{\text {OD }}$ & & & & & & & & \\
\hline Saman & 9 & 64,3 & 6 & 37,5 & 3 & 60,0 & 18 & 51,4 \\
\hline Toprak & 4 & 28,6 & 6 & 37,5 & 2 & 40,0 & 12 & 34,3 \\
\hline Kuru gübre & 0 & 0 & 2 & 12,5 & 0 & 0 & 3 & 5,7 \\
\hline Beton & 1 & 7,1 & 2 & 12,5 & 0 & 0 & 3 & 8,6 \\
\hline
\end{tabular}

${ }^{*} \mathrm{P}<0,05 .{ }^{\mathrm{OD}}$ Önemli değil.

Tablo 3 İşletme gruplarına göre ahır büyüklükleri ile inek başına düşen alana ait ortalama ve standart hataları

\begin{tabular}{|c|c|c|c|c|}
\hline \multirow[b]{2}{*}{ Özellikler } & \multicolumn{3}{|c|}{ İşletme grupları } & \multirow[b]{2}{*}{$\begin{array}{l}\text { Genel } \\
\bar{X} \pm S_{\bar{x}}\end{array}$} \\
\hline & $\begin{array}{l}\text { 1.grup } \\
\bar{X} \pm S_{\bar{x}}\end{array}$ & $\begin{array}{l}\text { 2.grup } \\
\bar{X} \pm S_{\bar{x}}\end{array}$ & $\begin{array}{l}\text { 3.grup } \\
\bar{X} \pm S_{\bar{x}}\end{array}$ & \\
\hline Ahir alanı $\left(\mathrm{m}^{2}\right)$ & $538 \pm 79^{c}$ & $1360 \pm 224^{b}$ & $2107 \pm 357^{\mathrm{a}}$ & $934 \pm 104$ \\
\hline İnek ahır alanı $\left(\mathrm{m}^{2}\right)$ & $259 \pm 23^{\mathrm{c}}$ & $570 \pm 53^{b}$ & $897 \pm 93^{\mathrm{a}}$ & $413 \pm 31$ \\
\hline İnek ahır alanı (inek/baş, m²) & $22,2 \pm 1,47$ & $19,5 \pm 1,70$ & $18,2 \pm 2,28$ & $21,0 \pm 1,05$ \\
\hline İnek sayısı (Baş) & $11,7 \pm 0,64^{\mathrm{c}}$ & $29,2 \pm 1,03^{\mathrm{b}}$ & $51,3 \pm 3,61^{\mathrm{a}}$ & $20,7 \pm 1,42$ \\
\hline İnek ahır kapasitesi (Baş) & $21,1 \pm 1,64^{\mathrm{c}}$ & $41,9 \pm 3,34^{\mathrm{b}}$ & $64,4 \pm 9,86^{\mathrm{a}}$ & $31,4 \pm 2,19$ \\
\hline İnek ahırı kapasite kullanımı (\%) & 55 & 70 & 80 & 66 \\
\hline Tam kapasitede alan ( inek/baș, $\mathrm{m}^{2}$ ) & $12,5 \pm 0,69$ & $13,5 \pm 0,93$ & $15,0 \pm 2,34$ & $13,0 \pm 0,54$ \\
\hline Hedeflenen inek sayısı (Baş) & $40,5 \pm 5,33^{\mathrm{b}}$ & $62,5 \pm 5,73^{\mathrm{b}}$ & $103,3 \pm 21,71^{\mathrm{a}}$ & $53,7 \pm 4,65$ \\
\hline Gezinme alanı $\left(\mathrm{m}^{2}\right)$ & $337 \pm 42$ & $730 \pm 95$ & $1090 \pm 261$ & $553 \pm 57$ \\
\hline Gezinme alanı (inek/baş, $\mathrm{m}^{2}$ ) & $30,7 \pm 3,99$ & $25,7 \pm 3,35$ & $22,4 \pm 6,05$ & $28,0 \pm 2,52$ \\
\hline Doğum bölmesi alanı $\left(\mathrm{m}^{2}\right)$ & $29 \pm 6,5$ & $28 \pm 5,5$ & $32 \pm 8,4$ & $29,3 \pm 3,7$ \\
\hline
\end{tabular}

${ }^{\mathrm{a}, \mathrm{b}, \mathrm{c}}$ Aynı satırda bulunan farklı harflerle gösterilen ortalamalar arasındaki farklılık önemlidir $(\mathrm{P}<0,05)$.

Ahırların alanı, inek başına düșen ahır alanı, ahır kapasitesi, gezinme alanı ve doğum bölmesi alanları Tablo 3 'te sunulmuştur. Birinci, 2. ve 3. grup işletmelerde ahırların ortalama büyüklükleri sırasıyla $538 \mathrm{~m}^{2}, 1360 \mathrm{~m}^{2}$ ve $2107 \mathrm{~m}^{2}$ dir $(\mathrm{P}<0,05)$. Sağmal inek ahırlarının büyüklükleri işletme gruplarına göre sırasıyla $259 \mathrm{~m}^{2}, 570$ $\mathrm{m}^{2}, 897 \mathrm{~m}^{2}$ 'dir $(\mathrm{P}<0,05)$. İşletme gruplarına $(1 ., 2$. ve 3. grup) göre inek başına düşen ortalama sağmal inek ahır alanlar1 sirasiyla $22,2 \mathrm{~m}^{2}, 19,5 \mathrm{~m}^{2}$ ve $18,2 \mathrm{~m}^{2}$ ve genel ortalama $21 \mathrm{~m}^{21}$ dir. İnek başına düşen gezinme alanı işletme gruplarına göre sirasıyla $29 \mathrm{~m}^{2}, 28 \mathrm{~m}^{2}$ ve 32 $\mathrm{m}^{2}$ 'dir (Tablo 3). Aydın'da ahır alanı bulgumuzdan daha küçüktür (771,7 m², ye karşın $934 \mathrm{~m}^{2}$ ) (Nizam, 2006). Ödemiş'te inek başına düşen alan, Kaymakçı ve Koçak (2002) tarafindan gezinme $\left(5-6 \mathrm{~m}^{2}\right)$ ve dinlenme $\left(5-6 \mathrm{~m}^{2}\right)$ yeri için bildirilenlerden yüksektir. Hayvan başına düşen alanın fazla olması, yağışlı dönemlerde çamur olma ve ayak hastalıklarına yakalanma riskini azaltmaktadır (Yaylak ve ark., 2010). Ayrıca, hayvanların doğru sosyal iletişim kurabilmesi için de ahır alanı yeterli olmalıdır (Hulsen, 2006). Çalışmamızda sağmal inek başına düşen alanın yüksek olmasının nedenleri serbest ahırların yörede yaygın olması ve ahır kapasitenin tam olarak kullanılamamasıdır. Ahır kapasitesinin kullanımı işletme 
gruplarına (1., 2. ve 3. grup) göre sirasıyla $\% 55, \% 70$ ve \%80'dir. Üçüncü gruptaki yetiştiricilerin ahırlarını daha yüksek kapasitede kullanmalarının nedenleri, yoğun yemi daha ucuza almaları ve sütü daha pahalıya satmaları olabilir. Nitekim, süt/yoğun yem paritesi 1., 2. ve 3. grup işletmelerde sırasıyla 0,$78 ; 0.88$ ve 0,95 'tir $(\mathrm{P}<0,05)$. Ahırların kapasiteleri dikkate alındığında hayvan başına 12,5 ile $15 \mathrm{~m}^{2}$ arasında alan düşmektedir.

Sürüsünü büyütmek isteyen yetiştiricilerin $(\% 70,7)$ sahip olmak istedikleri inek sayıları işletme gruplarına göre sırasıyla 40,5; 62,5 ve 103,3 baştır. Küçük işletmeler mevcut ineklerinin 3,5 katı kadar ineğe sahip olmak isterken, 2. ve 3 gruptaki yetiştiriciler mevcutun 2 katı kadar fazla ineğe sahip olmak istemişlerdir. Doğum bölmesi bulunan işletmelerde ortalama doğum bölmesi alanı $30 \mathrm{~m}^{2}$ civarında olup, ideal olarak bildirilen 12-14 $\mathrm{m}^{2}$ den (Akman, 2003) 2 kat daha büyüktür.

Ahırların aydınlatılması, aydınlatmada kullanılan araçlar ve aydınlatma nedenleri Tablo 4'te gösterilmiştir. Ödemiş’te ahırların çoğunun (\%91) yarı kapalı veya sundurmalı olması nedeniyle gündüz aydınlatmaya gerek yoktur. Yetiştiricilerin \%82,6'sı tarafindan ahırlar gece aydınlatılmaktadır. Birinci gruptaki işletmelerin \%29,1 gece aydınlatma yapmazken, diğer gruplardakilerin hepsi aydınlatma yapmışlardır $(\mathrm{P}<0,05)$. Uşak DSYB üyesi işletmelerin \%12'si ahırları aydınlatmıştır (Köse, 2006). Aydınlatmada en fazla florasan ve/veya tasarruf ampulü $(\% 73,7)$ kullanırken, ampul daha az $(\% 23,7)$ kullanılmıştır. Aydınlatmanın floresan ampullerle yapılması enerji tasarrufu açısından uygundur. Yetiştiriciler açısından en önemli aydınlatma nedeni işletmelerin güvenliği $(\% 56,6)$ olup bunu hayvanların gözlenmesi $(\% 26,3)$ ve yem tüketimini teşvik $(\% 17,1)$ takip etmiştir. Birinci ve 2 . grupta bulunan işletmelerde daha çok güvenlik nedeniyle aydınlatma yapılmıştır. Aydınlatma, çalışanların işlerini kolaylaştırma, hayvanları kontrol etme ve yem tüketimini teşvik etmek amacıyla yapılmalıdır (Akman, 2003; Görgülü, 2012).

Ödemiş'te yaz aylarında yüksek sıcaklıklar görülmektedir. Meteoroloji İşleri Genel Müdürlüğü verilerine göre İzmir İli uzun y1llar (1954-2013) Haziran, Temmuz, Ağustos ve Eylül aylarının en yüksek sıcaklık ortalamaları sirasiyla $30,8^{\circ} \mathrm{C} ; 33,2^{\circ} \mathrm{C} ; 32,8^{\circ} \mathrm{C}$ ve $29,0^{\circ} \mathrm{C}$ 'dir. Bu aylarda ekstrem hava sicaklıkları $40^{\circ} \mathrm{C}$ 'yi aşmaktadır. Çevre sıcaklığının $25-26^{\circ} \mathrm{C}$ 'nin üzerine çıkması hayvanların performanslarını düşürmektedir. Bölgede sığırları sıcaktan koruyucu ahırların yapılması uygundur. Sıcaklık stresinin etkisini azaltmak için barınak koşullarının iyileştirilmesi gölgelik yapma, fanla ve suyla serinletme gibi uygulamalarla mümkün olabilir (Oğan ve ark., 2011). Ödemiş'te yetiştiricilerin \%42,2'si hayvanları sicaklık stresinden korumak için hiçbir şey yapmazken $\% 26,1$ 'i su püskürtme (fiskiyeleme), \%21,7'si ahırın yanında gezinme alanının üzerini bir örtü malzemesi ile kapatma, \%8,7'si inekleri hortumla yıkama ve \%1,1'i de fanla serinletme yapmaktadirlar (Tablo 5).

Tablo 4 İşletmelerde ahırların aydınlatılması ile ilgili bilgiler

\begin{tabular}{|c|c|c|c|c|c|c|c|c|}
\hline \multirow[b]{3}{*}{ Özellikler } & \multicolumn{6}{|c|}{ İşletme grupları } & \multirow{2}{*}{\multicolumn{2}{|c|}{ Toplam }} \\
\hline & \multicolumn{2}{|c|}{ 1.grup } & \multicolumn{2}{|c|}{ 2. grup } & \multicolumn{2}{|c|}{ 3. grup } & & \\
\hline & $\mathrm{n}$ & $\%$ & $\mathrm{n}$ & $\%$ & $\mathrm{n}$ & $\%$ & $\mathrm{n}$ & $\%$ \\
\hline \multicolumn{9}{|l|}{ Gece aydınlatma durumu * } \\
\hline Evet & 39 & 70,9 & 29 & 100,0 & 8 & 100 & 76 & 82,6 \\
\hline Hayır & 16 & 29,1 & 0 & 0,0 & 0 & 0 & 16 & 17,4 \\
\hline \multicolumn{9}{|l|}{ Aydınlatmada kullanılan araçlar ${ }^{O D}$} \\
\hline Ampul & 9 & 23,1 & 8 & 27,6 & 1 & 12,5 & 18 & 23,7 \\
\hline Floresanve/veya tasarruf ampulü & 30 & 76,9 & 20 & 69,0 & 6 & 75,0 & 56 & 73,7 \\
\hline Projektör & 0 & 0,0 & 1 & 3,4 & 1 & 12,5 & 2 & 2,6 \\
\hline \multicolumn{9}{|l|}{ Aydinlatma nedeni ${ }^{O D}$} \\
\hline Güvenlik & 25 & 64,1 & 15 & 51,7 & 3 & 37,5 & 43 & 56,6 \\
\hline Yem tüketimini teşvik & 5 & 12,8 & 6 & 20,7 & 2 & 25,0 & 13 & 17,1 \\
\hline Gözlem yapmak & 9 & 23,1 & 8 & 27,6 & 3 & 37,5 & 20 & 26,3 \\
\hline
\end{tabular}

${ }^{*} \mathrm{P}<0,05 .{ }^{\mathrm{OD}}$ Önemli değil.

Tablo 5 İşletme gruplarına göre sı̆̆ırları sıcaklıktan korunmak için yapılanlar

\begin{tabular}{|c|c|c|c|c|c|c|c|c|}
\hline \multirow[b]{3}{*}{ Özellikler } & \multicolumn{6}{|c|}{ İşletme grupları } & & \\
\hline & \multicolumn{2}{|c|}{ 1.grup } & \multicolumn{2}{|c|}{ 2. grup } & \multicolumn{2}{|c|}{ 3. grup } & \multicolumn{2}{|c|}{ Toplam } \\
\hline & $\mathrm{n}$ & $\%$ & $\mathrm{n}$ & $\%$ & $\mathrm{n}$ & $\%$ & $\mathrm{n}$ & $\%$ \\
\hline Yaz sıcağından korunmak için ${ }^{\text {OD }}$ & & & & & & & & \\
\hline Hiçbirşey yapmayan & 21 & 38,2 & 14 & 48,3 & 4 & 50,0 & 39 & 42,2 \\
\hline İneği yıkayan & 6 & 10,9 & 2 & 6,9 & 0 & 0,0 & 8 & 8,7 \\
\hline Fiskiyeleme yapan & 13 & 23,6 & 9 & 31,0 & 2 & 25,0 & 24 & 26,1 \\
\hline Örtü malzemesi kullanan & 15 & 27,3 & 4 & 13,8 & 1 & 12,5 & 20 & 21,7 \\
\hline Fan kullanan & 0 & 0,0 & 0 & 0,0 & 1 & 12,5 & 1 & 1,1 \\
\hline
\end{tabular}


Tablo 6 İşletme gruplarına göre yem depoları ve suluklarla ilgili bilgiler

\begin{tabular}{|c|c|c|c|c|c|c|c|c|}
\hline \multirow[b]{3}{*}{ Özellikler } & \multicolumn{6}{|c|}{ İșletme grupları } & \multirow{2}{*}{\multicolumn{2}{|c|}{ Toplam }} \\
\hline & \multicolumn{2}{|c|}{ 1.grup } & \multicolumn{2}{|c|}{ 2. grup } & \multicolumn{2}{|c|}{ 3. grup } & & \\
\hline & $\mathrm{n}$ & $\%$ & $\mathrm{n}$ & $\%$ & $\mathrm{n}$ & $\%$ & $\mathrm{n}$ & $\%$ \\
\hline \multicolumn{9}{|l|}{ Yoğun yem deposu varlığ1 ${ }^{* *}$} \\
\hline Var & 29 & 52,7 & 22 & 75,9 & 8 & 100,0 & 59 & 64,1 \\
\hline Yok & 26 & 47,3 & 7 & 24,1 & 0 & 0,0 & 33 & 35,9 \\
\hline \multicolumn{9}{|l|}{ Kuru kaba yemlerin depolanma yerleri $^{\text {OD }}$} \\
\hline Üzeri açık & 4 & 7,3 & 1 & 3,4 & 0 & 0,0 & 5 & 5,4 \\
\hline Üzeri naylon örtülü & 15 & 27,3 & 12 & 41,4 & 1 & 12,5 & 28 & 30,4 \\
\hline Yem deposunda & 34 & 61,8 & 16 & 55,2 & 7 & 87,5 & 57 & 62,0 \\
\hline Ahır içinde & 2 & 3,6 & 0 & 0,0 & 0 & 0,0 & 2 & 2,2 \\
\hline \multicolumn{9}{|l|}{ Silaj deposu varlı̆̆ 1 OD } \\
\hline Var & 11 & 92,7 & 27 & 93,1 & 7 & 87,5 & 85 & 92,4 \\
\hline Yok & 4 & 7,3 & 2 & 6,9 & 1 & 12,5 & 7 & 7,6 \\
\hline \multicolumn{9}{|l|}{ Silaj deposu tipi* } \\
\hline Toprak zemin üstü naylon örtülü & 50 & 98,0 & 24 & 88,9 & 5 & 71,4 & 79 & 92,9 \\
\hline Beton zemin üstü naylon örtülü & 1 & 2,0 & 3 & 11,1 & 2 & 28,5 & 6 & 7,1 \\
\hline \multicolumn{9}{|l|}{ Suluk tipleri ${ }^{\mathrm{DD}}$} \\
\hline Beton yalak & 34 & 61,8 & 26 & 89,7 & 8 & 100 & 68 & 73,9 \\
\hline Teneke -bidon suluk & 14 & 25,5 & 3 & 10,3 & 0 & 0 & 17 & 18,5 \\
\hline Otomatik suluk & 3 & 5,5 & 0 & 0,0 & 0 & 0 & 3 & 3,3 \\
\hline Plastik bidon suluk & 4 & 7,3 & 0 & 0,0 & 0 & 0 & 4 & 4,3 \\
\hline Suluk temizleme siklığ 1 , gün $\left(\overline{\mathrm{X}}_{ \pm \mathrm{S}_{\bar{x}}}\right)$ & \multicolumn{2}{|c|}{$\frac{1}{13,1 \pm 2,32}$} & \multicolumn{2}{|c|}{$9,0 \pm 1,07$} & \multicolumn{2}{|c|}{$11,5 \pm 1,71$} & \multicolumn{2}{|c|}{$11,7 \pm 1,44$} \\
\hline
\end{tabular}

\section{İncelenen İşletmelerde Kaba ve Yoğun Yem Depoları}

İşletmelerin yem depolama ve suluk yapısıyla ilgili bilgileri Tablo 6'da gösterilmiştir. İşletmelerin \%64,1'inde yoğun yem deposu bulunmaktadır $(\mathrm{P}<0,01)$. Yetiştiricilerin \%62'si kaba yemleri yem deposunda, $\% 30,4$ 'ü üzeri naylon ile örtülü halde ve $\% 5,4$ 'ü ise açıkta depolamaktadır. Sürü büyüklüğü artışına bağlı olarak kaba ve yoğun yemleri yem deposunda saklayan yetiştiricilerin oranı yükselmiştir. Oluğ (1996) Burdur'daki işletmelerin \%86,2'sinde kaba yem deposunun bulunduğunu bildirirken, daha sonraki yıllarda Burdur'da kaba yemlerin işletmelerin \%48'inde yem deposunda, \%36'sında üzeri saç ile kaplı duvarsız alanlarda, \%7'sinde ahır içerisinde ve \%1'inde doğal ortamda açık şekilde depolandıkları bildirilmiştir (Karakaş Oğuz ve ark., 2012). İșletmelerin \%92,4'ünde silaj deposu bulunmakta olup, bunların \%92,9'unda toprak zeminli üstü naylon örtülü silaj deposu vardır. Sürü büyüklüğü arttıç̧a beton zeminli üstü naylon örtülü silolara sahip olma oranı (\%2'den \%25'e) yükselmiștir.

İşletmelerde bulunan sulukların \% 73,9'u beton yalak, $\% 18,3$ 'ü teneke bidon, \%4,3'ü plastik bidon ve \%3,3'ü otomatik suluktur. Birinci, 2. ve 3. grup işletmelerde beton yalak tipi suluk bulundurma oranları sirasıly $\% 61,8 ; \% 89,7$ ve $\% 100$ 'dür. Beton yalak tipi suluklar, Burdur ve Aydın illerindeki yetişticiler tarafından da en fazla tercih edilen suluk tipidir (Oluğ, 1993; Payık ve Kaya kuyululu, 2012). Aydın'daki işletmelerde bulunan otomatik suluk sistemi oransal olarak Ödemiş'in üç (\%3,3'e karşı \%11) katından fazladır (Payık ve Kaya kuyululu, 2012). Suluklar ortalama 12 günde bir temizlenmektedir. Mikropların üremesi ve hastalı̆̆ kolaylıkla yaymaları nedeniyle sulukların temizliği daha sık yapılmalıdır. Ayrıca sığırlar salya kokusunu sevmezler, bu nedenle suluklar sik temizlenmelidir (Hulsen, 2006).

\section{İncelenen İşletmelerde Sağım Sistemleri}

İşletmelerde bulunan sağım üniteleri, sütün sağıldığı yer, soğutma tankı ve sağım başlığı sayısına ait bilgiler Tablo 7'de gösterilmişsir. İşletmelerin tümünde sağım makinesi bulunmaktadır. Sağım sistemleri içinde en yaygin olanı seyyar kovalı $(\% 47,8)$ sistem olup, bu sistemi sirasiyla vakum hatll/boru hatlı (kovaya veya tanka sağım) sistem $(\% 37)$ ve sağımhane $(\% 15,2)$ takip etmektedir $(\mathrm{P}<0,05)$. Seyyar kovalı makinelerle sağım 1 . ve 2. grup işletmelerde yapilırken, 3. grup işletmelerde diğer sistemler bulunmaktadır. Uşak, Burdur ile Ankara ve Aksaray'da sağım makinesi bulunan yetiștiricilerin büyük çoğunluğu seyyar sağım makinası ile sağım yapmaktadırlar (Köse, 2006; Elmaz ve ark., 2010). Bu araştırmalardaki sürüler çalışmamızdakilerden küçüktür. Sağılacak inek sayısı, sağım sisteminin belirlenmesinde en önemli faktördür. Seyyar sağım makinası 5-10 ineği bulunan işletmeler için uygundur. Çalışmamızda yetiştiricilerin tamamının makineli sağım yapmasının nedeni sürülerin büyük olması ve daha önce de makinalı sağımın yörede yaygın $(\% 65 ;$ Koyubenbe 2005) yapilmasidır.

Süt kalitesinin korunması öncelikle sağım sırasında hijyen kurallarına uyulmasına ve sütün soğutulmasına bağlıdır. Diğer yandan soğuk sütün satış fiyatı daha yüksektir. İşletmelerde sütün $\% 73,9$ 'u güğüme, $\% 26,1$ 'i tanka sağılmaktadır. Sürüler büyüdükçe süt soğutma tank1 kullanımı artarak 3. grup işletmelerde \%100'e ulaşmıştır. Bazı araştırıcılar (Soyak ve ark. 2007; Tatar, 2007; Payık ve Kaya kuyululu, 2012) Tekirdağ, Aydın ve Ankara da süt soğutma tankı bulunan işletmelerin oranını (\%4 ile $\% 19,4)$ bulgumuzdan daha düşük saptamışlardır. Süt soğutma tanklarının ortalama kapasitesi işletme gruplarına göre sirasıyla 1,$0 ; 1,2$ ve 1,7 ton, genel ortalama 1,3 ton'dur. Aydın da süt tanklarının ortalama kapasitesi 1,5 ton olup bulgumuzdan biraz büyüktür 
(Payık ve Kaya Kuyululu, 2012). Çalışmamızda süt soğutma tankı olmayan (68 adet) işletmeler sütlerini gügümlerde bekleterek satmaktadır. Süt gügüumlerinin $\% 37,1$ 'i krom çelik, \%21,4'ü plastik, \%18,6's1 alüminyum ve geriye kalanı da karışıktır (çelik ve/veya plastik ve/veya alüminyum güğüm). Krom çelik dişındaki güğümlerde sütlerin bekletilmesi uygun değildir.

Birinci, 2. ve 3. grup işletmelerde bulunan ortalama sağım başlığı sayıları sırasıyla 2,4; 4,6 ve 7,8 adettir $(\mathrm{P}<0,05)$. Sağım başlığı başına düşen ortalama sağmal inek sayıları 1. 2. ve 3. grup işletmelerde sırasıyla 4,4; 6,6 ve 7,0 baştır. İşletmeler büyüdükçe seyyar makine kullanımı azalmış ve sağım başlığı başına düşen inek sayısı artmıştır. Sürüler büyüdükçe sağım makinalarının daha verimli kullanıldığı söylenebilir. Sağımhane yönetiminin başarı göstergelerinden birisi, bir saatte sağılan hayvan sayısının sağım başlığının 7-8 katından küçük olup olmamasıdır (Akman, 2003). Bu kritere göre işletme grupları ortalama hayvan sayıları dikkate alındığında sağımlar bir saatten önce bitirilmektedir. Sağım başlı̆̆ı başına sağılan inek sayısı seyyar, vakum hatlı ve/veya boru hatlı ve sağımhane sistemlerinde sırasıyla 5,$2 ; 5,8$ ve 4,8 baştır. Sağılan inek sayıları seyyar, vakum hatlı ve/veya boru hatlı ve sağımhane sistemlerinde sirasıyla 10,4; 21,5 ve 27,1 baştır $(\mathrm{P}<0,05)$.

Tablo 7 İşletmelerde sağım üniteleri, sütün sağıldığı yer, soğutma tankı ve sağım başlığı sayısı

\begin{tabular}{|c|c|c|c|c|c|c|c|c|}
\hline \multirow[b]{3}{*}{ Özellikler } & \multicolumn{6}{|c|}{ İşletme grupları } & \multirow{2}{*}{\multicolumn{2}{|c|}{ Toplam }} \\
\hline & \multicolumn{2}{|c|}{ 1.grup } & \multicolumn{2}{|c|}{ 2. grup } & \multicolumn{2}{|c|}{ 3. grup } & & \\
\hline & $\mathrm{n}$ & $\%$ & $\mathrm{n}$ & $\%$ & $\mathrm{n}$ & $\%$ & $\mathrm{n}$ & $\%$ \\
\hline \multicolumn{9}{|l|}{ Sağım sistemi ${ }^{*}$} \\
\hline Seyyar güğümlü (kovalı) & 39 & 70,9 & 5 & 17,2 & 0 & 0 & 44 & 47,8 \\
\hline Sağımhane & 1 & 1,8 & 10 & 34,5 & 3 & 37,5 & 14 & 15,2 \\
\hline Vakum hatlı ve/veya boru hatlı & 15 & 27,3 & 14 & 48,3 & 5 & 62,5 & 34 & 37,0 \\
\hline \multicolumn{9}{|l|}{ Sağım sistemi ve sütün sağıldı̆̆ 1 yer $* *$} \\
\hline Seyyar kovalı & 39 & 70,9 & 5 & 17,2 & 0 & 0 & 44 & 47,8 \\
\hline Vakum hatl1 sistem- kova & 12 & 21,8 & 8 & 27,6 & 0 & 0 & 20 & 21,7 \\
\hline Vakum hatl1 sistem-tank (boru hatl1) & 3 & 5,5 & 6 & 20,7 & 5 & 62,5 & 14 & 15,2 \\
\hline Sağımhane-kova & 0 & 0 & 3 & 10,3 & 1 & 12,5 & 4 & 4,3 \\
\hline Sağımhane-tank & 1 & 1,8 & 7 & 24,1 & 2 & 25 & 10 & 10,9 \\
\hline \multicolumn{9}{|l|}{ Sütün sağ $1 l_{1}{ }_{1} \breve{g}_{1}$ yer * } \\
\hline Kovaya & 51 & 92,7 & 16 & 55,2 & 1 & 12,5 & 68 & 73,9 \\
\hline Tanka & 4 & 7,3 & 13 & 44,8 & 7 & 87,5 & 24 & 26,1 \\
\hline \multicolumn{9}{|l|}{ Süt soğutma tankı varlığ ${ }^{*}$} \\
\hline Var & 4 & 11,0 & 13 & 37,9 & 7 & 87,5 & 24 & 26,1 \\
\hline Yok & 51 & 89,0 & 16 & 62,1 & 1 & 12,5 & 68 & 73,9 \\
\hline \multicolumn{9}{|l|}{ Tank dıșında sütün saklandığı güğüm tipi ${ }^{O D}$} \\
\hline Çelik & 18 & 35,3 & 6 & 37,5 & 1 & 100,0 & 25 & 36,7 \\
\hline Alüminyum & 12 & 23,5 & 1 & 6,3 & 0 & 0,0 & 13 & 19,1 \\
\hline Plastik & 10 & 19,6 & 5 & 31,3 & 0 & 0,0 & 15 & 22,1 \\
\hline Karışık & 11 & 21,6 & 4 & 25,0 & 0 & 0,0 & 15 & 22,1 \\
\hline Süt soğutma tank1 kapasitesi, $\mathrm{t}\left(\overline{\mathrm{X}}_{ \pm \mathrm{S}_{\overline{\mathrm{x}}}}\right)$ & \multicolumn{2}{|c|}{$1,0 \pm 0,5$} & \multicolumn{2}{|c|}{$1,2 \pm 0,2$} & \multicolumn{2}{|c|}{$1,7 \pm 0,1$} & \multicolumn{2}{|c|}{$1,3 \pm 0,1$} \\
\hline Sağım başlığ sayısı, adet $\left(\bar{X}_{ \pm} S_{\bar{x}}\right)$ & \multicolumn{2}{|c|}{$2,4 \pm 0,16^{\mathrm{c}}$} & \multicolumn{2}{|c|}{$4,6 \pm 0,507^{\mathrm{b}}$} & \multicolumn{2}{|c|}{$7,8 \pm 1,346^{\mathrm{a}}$} & \multicolumn{2}{|c|}{$3,6 \pm 0,274$} \\
\hline Sağım başlığı başına düşen inek sayısı $\left(\bar{X}_{ \pm} S_{\bar{x}}\right)$ & \multicolumn{2}{|c|}{$4,4 \pm 0,26^{\mathrm{b}}$} & \multicolumn{2}{|c|}{$6,6 \pm 3,39^{\mathrm{a}}$} & \multicolumn{2}{|c|}{$7,0 \pm 2,91^{\mathrm{a}}$} & \multicolumn{2}{|c|}{$5,3 \pm 0,29$} \\
\hline
\end{tabular}

Tablo 8 Gübrenin depolama yeri ve depolama süresi

\begin{tabular}{|c|c|c|c|c|c|c|c|c|}
\hline \multirow[b]{3}{*}{ Özellikler } & \multicolumn{6}{|c|}{ İşletme grupları } & \multirow{2}{*}{\multicolumn{2}{|c|}{ Toplam }} \\
\hline & \multicolumn{2}{|c|}{ 1.grup } & \multicolumn{2}{|c|}{ 2. grup } & \multicolumn{2}{|c|}{ 3. grup } & & \\
\hline & $\mathrm{n}$ & $\%$ & $\mathrm{n}$ & $\%$ & $\mathrm{n}$ & $\%$ & $\mathrm{n}$ & $\%$ \\
\hline Gübrenin depolandığı yer ${ }^{\text {OD }}$ & & & & & & & & \\
\hline Yakında yığın halde & 45 & 81,8 & 24 & 82,8 & 7 & 87,5 & 76 & 82,6 \\
\hline Tarlaya & 10 & 18,2 & 5 & 17,2 & 2 & 12,5 & 16 & 17,4 \\
\hline Gübre depolama süresi ${ }^{\text {OD }}$ & & & & & & & & \\
\hline $0-1$ ay & 9 & 20,0 & 2 & 8,3 & 0 & 0 & 11 & 14,5 \\
\hline $2-6$ ay & 26 & 57,8 & 15 & 62,5 & 7 & 100,0 & 48 & 63,2 \\
\hline 7 ay + & 10 & 22,2 & 7 & 29,2 & 0 & 0 & 17 & 22,4 \\
\hline
\end{tabular}




\section{Incelenen Issletmelerde Gübrelikler}

Hayvan her gün canlı ağırlığının \%6 ile 13’ü kadar katı ve sıvı gübre üretmektedir (Akman, 2003). Günümüzde gübre, kokusu ve sineklerin üremesine uygun olması nedeniyle yerleşim yerlerinde rahatsızlıklara ve çevre kirliliğine yol açmaktadır. Diğer yandan, uygun koşullarda depolanmayan gübrede besin madde kayıları meydana gelmektedir. Çalışmanın yürütüldüğü işletmelerin hiçbirisinde gübre çukuru bulunmamaktadır. Kars ilinde ise işletmelerin \%16'sında gübre çukuru bulunmaktadır (Tilki ve ark., 2013). İşletmelerin \%82,6’s1 gübreyi ahırına yakın bir yerde yığın halinde ve \%17,4'ü tarlasında depolamaktadır (Tablo 8). Burdur ilinde de yetiştiriciler gübreyi önce ahır yakınında biriktirmekte daha sonra tarlaya atmaktadir (Elmaz ve ark., 2010). Ödemiş’te yetiştiriciler ahırlarındaki gübreyi yaz ve sonbahar mevsimlerinde ortalama 74 günde bir temizlerken, kıș ve ilkbahar mevsimlerinde ortalama 49 günde bir temizlemektedir. Gübreyi işletmelerine yakın bir yerde 2-6 ay süreyle depolayan yetiştiricilerin oranı $\% 63,2$ iken, 7 aydan uzun süre depolayanların oranı \%22,4'dür. Avluda ve ahırın dişında bulunan gübreler çamur veya toprakla karışarak ve yağmurlarla değerli kısımlarını kaybederler (Özhan ve ark., 2007). Ankara'da gübreliklerin \%51,7'si 1 y1l ve üzerinde bir süre depolandiktan sonra, Aksaray'da ise \%53,2'si 3-6 ay depolandıktan sonra boşaltılmaktadır (Tatar, 2007). Ahır avlusunda 3 ile 6 ay arasında biriktirilen gübrenin değeri, iyi bir şekilde saklanan veya doğrudan tarlaya atılan gübrenin yarısı veya üçte biri kadar olmaktadır (Özhan ve ark., 2007). Ödemiş’te gübrelerin uygun koşullarda depolanmaması nedeniyle önemli düzeyde besin kaybettiği söylenebilir.

\section{Sonuç}

Süt sığırcılığı açısından önemli bir yer olan İzmir İli Ödemiş ilçesinde Damızlık Sığır Yetiştiricileri Birliği üyesi işletmelerde yürütülen çalışmamızda ahırlar, kaba ve yoğun yem depoları, sağım üniteleri ve gübrelik bulunma durumları araştırılmıştır. Sürü büyüklügüünü artması ile sundurmalı ve serbest ahırlar, sağmal ve diğer dişilerin ayrı barındırılması, buzağıların bireysel barındırılması, doğum bölmesi bulunması, yoğun ve kaba yem deposunun varlığı, beton yalak tipi suluk bulunması, süt soğutma tankının bulunması, sağım başlıkları ile daha fazla ineğin sağılması ve ahırların gece aydınlatılmasında iyileşmeler olduğu ortaya çıkmıştır. Sonuç olarak; sürü büyüklüğünün artması ile sığırların barınma koşullarının iyileştiği söylenebilir.

\section{Teşekkür}

Projenin (2007-OMYO-002) yürütülmesinde parasal kaynağı temin eden EBİLTEM'e, İzmir Damızlık Sığır Yetiştiricileri Birliği'ne, ankete katılan süt sığırı yetiştiricilerine teşekkürü borç biliriz.

\section{Kaynaklar}

Akman N. 2003. Pratik Sı̆̆ır Yetiştiriciliği. Türk Ziraat Mühendisleri Birliği Vakfi Yayını

Bardakçığlu HE, Türkyılmaz MK, Nazlıgül A. 2004. Aydın İli süt sığırcılık işletmelerinde kullanılan barınakların özellikleri üzerine bir araştırma. İstanbul Üniv. Vet. Fak. Der., 30: 51-62.
Daş A, İnci H, Karakaya E, Şengül AY. 2014. Bingöl İli damızlık sığır yetiştiricileri birliğine bağlı sığırcılık işletmelerinin mevcut durumu. Türk Tarım ve Doğa Bilimleri, 3: 421-429.

Elmaz Ö, Saatc1 M, Özçelik MM, Sipahi C. 2010. Burdur İli Süt Sığırcilığı ve Özellikleri. Mehmet Akif Ersoy Üniversitesi, 0038-NAP-08 no'lu proje.

Erdoğan HM, Çitil M, Güneş G, Saatci M. 2004. Dairy cattle in Kars district, Turkey: I. Characteristics and production. Turk J. Vet. Anim. Sci., 28: 735-743.

Görgülü M. 2012. Süt Sı ̆̆ırlarının Beslenmesi ve Yemler. Ed. Kumlu S., AB ve Türkiye'de Danışmanlık Sistemleri ve Süt Sığırı İşletmelerinin Yönetimi, Cilt 1. 123-198.

Hulsen J. 2006. Cow signals. The Practical guide for dairy cow management. Canada-USA edition. Bergen op Zoom, The Netherlands.

Karakaş Oğuz F, Oğuz, MN, Sipahi C, Çiçek M. 2012. Süt üretiminde Maliyet, Durum Tespiti ve Eğitim Faaliyetleri. Burdur.

Kaygısız A, Tümer R. 2009. Kahramanmaras İli süt sığırı isletmelerinin yapısal özellikleri 2. Barınak özellikleri. KSÜ Doğa Bil. Derg., 12: 40-47.

Kaymakçı M, Koçak Ç. 2002. Tarımsal Uygulamalar "Hayvansal Üretim Uygulamaları" Ege Üniv. Zir. Fak. Yay. No: 552.

Koyubenbe N. 2005. İzmir İli Ödemiş İlçesinde süt sığırcılığının geliştirilmesi olanakları üzerine bir araştırma. Hayvansal Üretim Dergisi, 46: 8-13.

Köse K. 2006. Uşak İli damızlık sığır yetiştiriciler birliğine kayıtlı işletmelerin genel yapısı. Trakya Üniv. Fen Bil. Enst., Yük. Lis. Tezi.

Miran B. 2002. Temel İstatistik. Ege Üniv. Basım Evi, İzmir

Nizam S. 2006. Aydın İlinde pazara yönelik süt sığırcılığı işletmelerinin verimliliklerinin belirlenmesi. Adnan Menderes Üniv. Fen Bil. Enst. Yük. Lis. Tezi.

Oğan M, Petek M, Dikmen S, Orman A, Alpay F, Üstüner H. 2011. Temel Zootekni. Anadolu Üniversitesi Yayın No: 2316. Açıöŏgretim Fakültesi Yayın No: 1313.

Oluğ HH. 1996. Burdur süt sığırcılığının sorunları ve çözüm önerileri. Akdeniz Üniv. Fen Bil. Enst. Yük. Lis. Tezi.

Özhan M, Tüzemen N, Yanar M. 2007. Büyükbaş hayvan yetiştirme (süt ve et sığırcılığı). Atatürk Üniversitisi Ziraat Fakültesi Yayınları, Ders Notu Yayın No: 134. 5. Bask1.

Öztürk İ, Ünal HB. 2011. Evaluation of manure management in dairy cattle farms: The case of İzmir - Tire (Turkey) Region. Kafkas Üniv. Vet. Fak. Derg., 17: 741-747

Payık ES, Kaya Kuyululu Ç. 2012. Aydın İlinde sığır yetiştiriciliği. Ed. Kumlu S., AB ve Türkiye'de danışmanlık sistemleri ve süt sığırı işletmelerinin yönetimi Cilt-1. P 5-38.

Saner G. 1993. İzmir yöresinde pazara yönelik süt sığırcılığ işletmelerinin ekonomik açıdan değerlendirilmesi üzerine bir araştırma. Ege Üniv. Fen Bil. Enst., Dok. Tezi.

Soyak A, Soysal Mİ, Gürcan EK. 2007. Tekirdağ ili süt sığırcılığı işletmelerinin yapısal özellikleri ve bu işletmelerdeki Siyah Alaca süt sı̆̆ırlarının çeşitli morfolojik özellikleri üzerine bir araştırma. Tekirdağ Zir. Fak. Derg., 4: 297-305.

SPSS. 1999. Version 10.0. SPSS Inc., Wacker Drive, Chicago, IL, USA.

Şeker İ, Tasalı H, Güler H. 2012. Muş İlinde sığır yetiştiriciliği yapılan işletmelerin yapısal özellikleri. Fırat Üniv. Sağ. Bil. Vet. Derg., 26: 9-16.

Tatar AM. 2007. Ankara ve Aksaray damızlık sığır yetiştiricileri il birliklerine üye süt sığırcılığı işletmelerinin yapısı ve sorunları. Ankara Üniv. Fen Bil. Enst., Doktora Tezi.

Tilki M, Sarı M, Aydın E, Işıı S, Aksoy AR. 2013. Kars İli Sığır İşletmelerinde Barınakların Mevcut Durumu ve Yetiştirici Talepleri: I. Mevcut Durum. Kafkas Üniv. Vet. Fak. Derg., 19: 109-116. 
Tugay A, Bakır G. 2004. Giresun Yöresindeki özel süt sığırcılığı işletmelerinin ırk tercihleri ve barınakların yapısal durumu. 4. Ulusal Zootekni Bilim Kongresi. 01-03 Eylül 2004. S: 390-397.

Yaslıoğlu E, Arıcı İ. 2005. Bursa bölgesinde süt sığırcılığına uygun soğuk ahır tiplerinin geliştirilmesi üzerine bir araştırma. Tekirdağ Zir. Fak. Derg., 2: 95-114.

Yaylak E, Akbaş Y, Kaya İ, Uzmay C. 2010. The effects of several cow and herd level factors on lameness in holstein cows reared in Izmir province of Turkey. JAVA, 9: 27142722.

Yener H, Atalar B, Mungan M. 2013. Şanlıurfa İlindeki sığırcılık işletmelerinin biyogüvenlik ve hayvan refahı açısından değerlendirilmesi. Harran Univ. Vet. Fak. Derg., 2: 87-93.

Yüksel AN, Soysal Mİ, Kocaman İ, Soysal Sİ. 2004. Süt sı ̆̆ırcılığı temel kitabı (süt sığırı ahırlarının planlanması/süt sığırı yetiştiriciliği). Hasad Yayıncılık Ltd. Şti., İstanbul. 